\title{
The Use of a Dynamic Cooling Mechanism for a Double Faced Photovoltaic Power System
}

\author{
${ }^{1}$ Muhammed Selman EREL, ${ }^{2}$ Şerafettin EREL \\ Ankara Yildirim Beyazit University, Faculty of Engineering and Natural Sciences, Department of Electrics \& \\ Electronics Engineering, Etlik, Ankara, TURKEY
}

\begin{abstract}
The use of solar energy systems among renewable energy sources is gaining importance day by day. Photovoltaic systems have a special importance among solar energy systems. Although the incident light flux increases the electrical energy produced in the solar panels, the increase in temperature caused by the radiation reduces the efficiency of the solar panels. Important methods are being studied in order to increase this falling efficiency. Dynamic cooling systems are one of the important methods used in this field. In this study, a dynamic cooling mechanism was designed and developed for a double-faced photovoltaic power generation system. From this point, it was concluded that temperature is one of the important factors affecting the efficiency of solar panels.
\end{abstract}

Keywords: Solar energy, photovoltaic cell, efficiency, cooling system, temperature

\section{Introduction}

Energy demand of the world is increasing year by year. Majority of the energy supply depends on fossil-fuel resources. This dependence brings environment pollution and limited resource issues. Researchers continue with renewable energy resources to solve this issue. Solar energy resources are the most dominant one in renewable energy resources. Importance of them are increasing day by day. Photovoltaic systems sit on the special place at solar energy resources. A general purpose silicon photovoltaic panel can convert 6-20\% of incoming sunlight [1]. Many researchers and professionals in rush to increase electrical performance of photovoltaic panels. There are many parameters affecting PV module electrical performance: Structural material of module, temperature, humidity, wind etc. Temperature is the most important environmental parameter. Some part of the spectrum is converted to electricity other part of it converts to heating. Photovoltaic parameters like open-circuit voltage, short circuit current, maximum output power, fill factor and efficiency are influenced by cell temperature. However, maximum influence is seen in the open circuit voltage. In addition, based on the universal photovoltaic standard of EN 60904-5, if temperature effect of solar cell is desired to observe, variation of output voltage should be measured.

Desire to obtain higher output power from photovoltaics bring cooling issue. Concentrated photovoltaic systems can give multiple even hundreds times of power by stand alone photovoltaic panels. On the other hand, concentration of multiple sun power increases operating temperature of photovoltaic panels. Cooling of panels is only way to reduce the operating *Corresponding author: Address: Faculty of Engineering and Natural Sciences, Department of Electrical and Electronics Engineering Yildirim Beyazit University, 06010, Ankara TURKEY. E-mail address: mselmanerel@gmail.com, Phone: +903129062202 
temperature of solar cells. There are many cooling methods to improve photovoltaic efficiency. Basically, they are categorized as active cooling or passive cooling based on extra power consumption. Forced water cooling, forced air cooling, thermoelectric cooling, nano fluid cooling and micro channel cooling are active cooling methods. Heatsink cooling, immersion liquid cooling, phase change material (PCM) cooling, heat pipe cooling and radiative cooling are passive cooling methods. Active cooling methods provide higher efficiency increase than passive cooling methods. Force air cooling, aka. fan cooling, is the most simple, easiest to maintain but robust cooling method among active cooling methods. In this study, effect of temperature on photovoltaic performance is observed and modeled. Also, by using developed solar simulator system, cooling effect is observed.

Temperature dependent efficiency expressions are reviewed [1]. Also, the most used experiments by Evans Florschuetz PV efficiency correlation coefficient in literature is reviewed. Estimation of operating temperature of solar cell is made by utilizing BP-ANN due to difficulty of online measurement [2]. However, calculation of efficiency as an important figure of merit is not a good attitude. In reference [3], author observed the effect of irradiance and temperature on open circuit output voltage, variation of photovoltaic parameters [4] is observed. Also, variation of short circuit current is interesting observation. Different type of PV modules [5] are compared with each other and under different systems like sun tracking etc. In reference [6], author, explained how solar cells are affected physically as temperature increases. He explained how parameters change depending on temperature. Estimation models of operating temperature of solar module [7] are studied. Also, they proposed a new model for estimation and validated their model with an experiment. Meanwhile, a model to estimate efficiency is proposed [8] and also they proposed a model to estimate efficiency. Their model depends also on irradiance, which means it is more sensitive. They compared their model with other models. Moreover, thermal modelling of PV module is proposed [9] and also the proposed model is validated with an experiment. Based on this modelling, module temperature is estimated. However, structurally paper seems as complex. Simplification is required. Additionally, photovoltaics in power system [10] and the factors affecting efficiency of solar cells are studied significantly [11]. Variations of not only solar cell parameters but also equivalent circuit parameters of solar cell are modelled. Experimentally, they are validated [12]. Temperature dependency of PV module parameters are analyzed [13] and also apart from other studies, all parameters are analyzed in terms of reverse saturation current and how this current affects other parameters is investigated. Besides, temperature and power correlations between temperature and efficiency are investigated [14]. As being a comprehensive review, it is a valuable work.

This study comprises of four sections: Introduction, materials and method, results and discussion, conclusion. In introduction section, brief information about photovoltaics is given. temperature vs. performance issue is explained. Literature search is given. In materials and method section, mathematical explanation of temperature dependence of photovoltaic performance is given. Proposed system model to solve the temperature issue is given. Details about proposed system are given. Instruments utilized in experiment are introduced. In results and discussion section, experimental results are depicted. Discussion about experimental results is done. In conclusion section, thermal dependency of photovoltaic performance is restated. Proposed system is restated. Possible future developments of the system is stated. 


\section{Materials and Method}

Temperature is the most important parameter which affects the performance of solar cells. In literature, there are many models derived to indicate temperature effect on PV module efficiency [4,6-8,12-14]. In literature, the most-cited and the most used efficiency model and open circuit output voltage relation are given below:

$$
\begin{gathered}
\eta_{c}=\eta_{\text {Tref }}\left[1-\beta_{\text {ref }}\left(T_{c}-T_{r e f}\right)+\gamma \log _{10} G_{T}\right] \\
V_{o c}=\frac{E_{g}}{q}-\frac{n k T}{q}\left(\ln \frac{I_{0, \max }}{I_{s c}}\right)
\end{gathered}
$$

$\eta_{c}$ is cell efficiency, $\eta_{\text {Tref }}$ is efficiency at reference case, $\beta_{\text {ref }}$ is temperature coefficient, $\gamma$ is solar radiation coefficient and $G_{T}$ is solar radiation flux on module plane. In (1), efficiency depends on both structural and environmental parameters. It is not an easy job to modify structural parameters. Then, environmental parameters are only ones to go with. Changing irradiance is not possible excluding concentration. Temperature is the only parameter to change. Many studies are done to change operating temperature of PV module. In this study, fan cooling system is chosen because it is simple to install but robust. Theoretical model of proposed cooling system is given below:

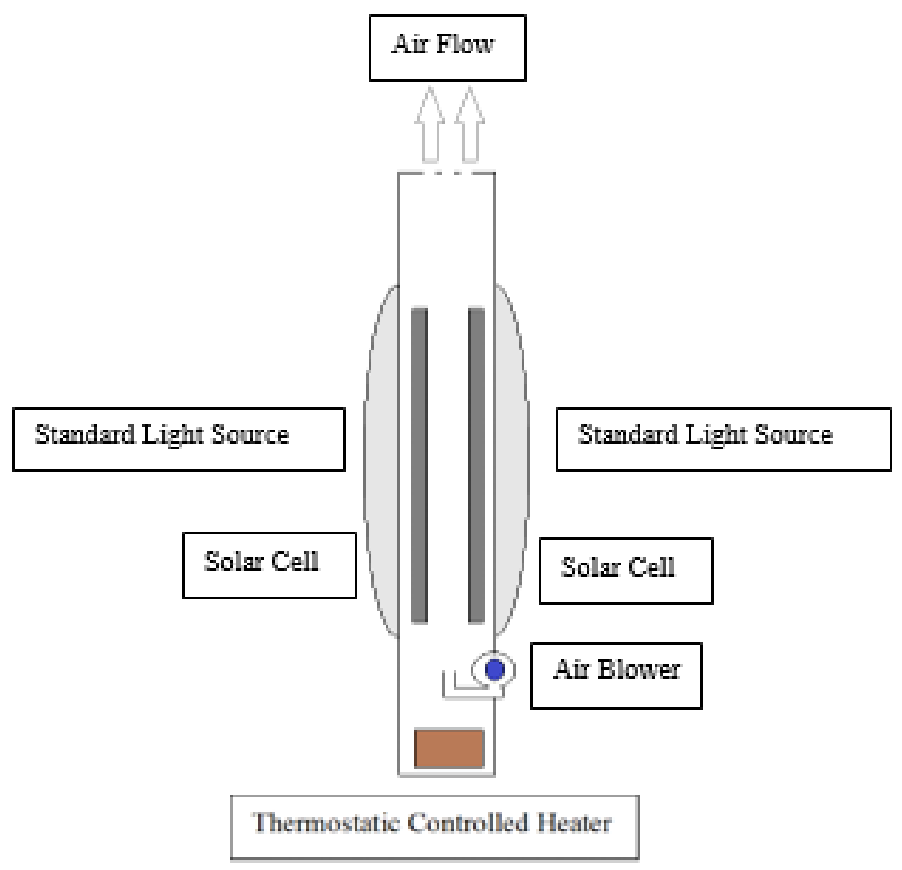

Figure 1. Proposed System Model 
Two identical standard light sources are utilized to illuminate two identical solar cells. Air blower is used for fan cooling. Thermostatic controlled heater is utilized to change environment temperature. Overview of simulator and cooling system is given below:

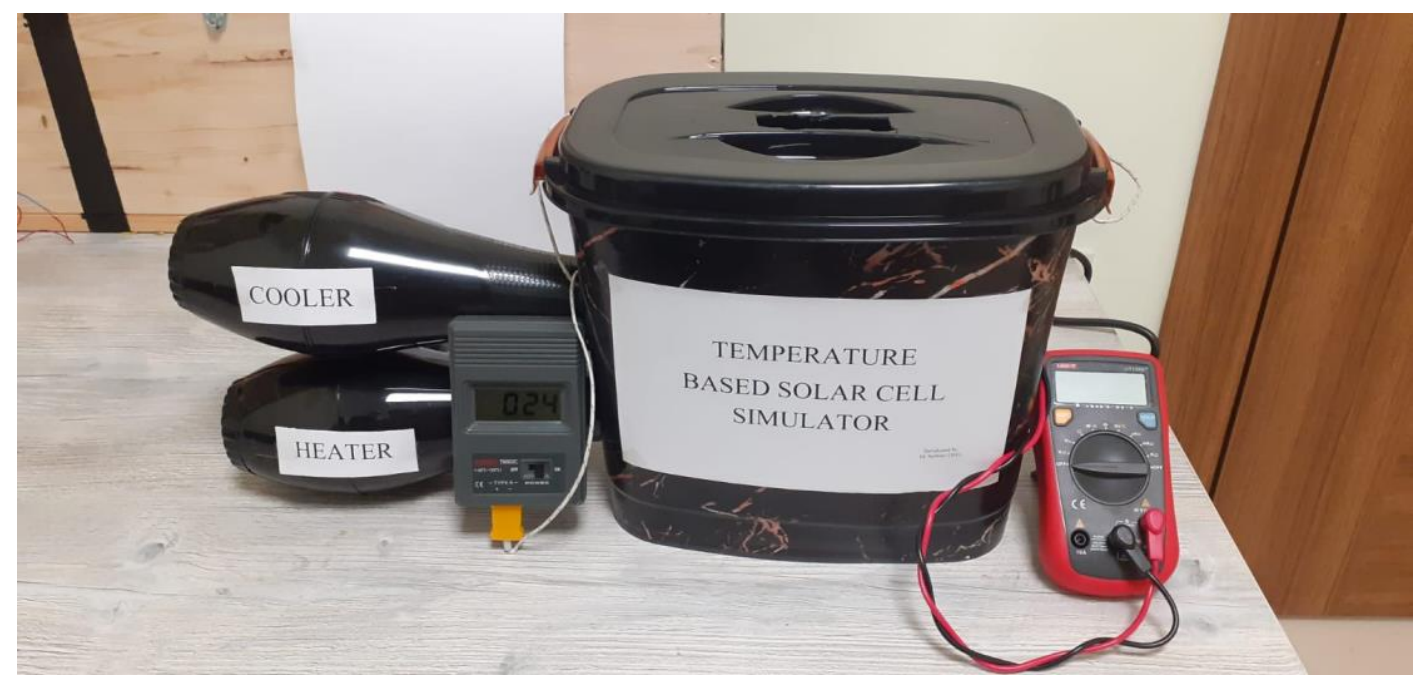

Figure 2. Overview of Solar Simulator and Cooling System

First, under constant identical two illumination sources, two identical solar panels are illuminated. Ambient temperature is recorded. Then, by gradually activating heating system, solar system temperature is recorded, corresponding open circuit output voltages of PV modules are recorded. By activating cooling system, solar simulator temperature reaches to optimum ambient temperature.

Instruments utilized to obtain experimental data are given as below:

Table 1. Electrical Equipment Configuration of Solar Simulator Cooling System

\begin{tabular}{c}
\hline Instrument Class \\
Solar Panel \\
$20 \mathrm{~cm} \mathrm{x} 13 \mathrm{~cm} 12 \mathrm{~V} 500$ \\
$\mathrm{mAh}$
\end{tabular}




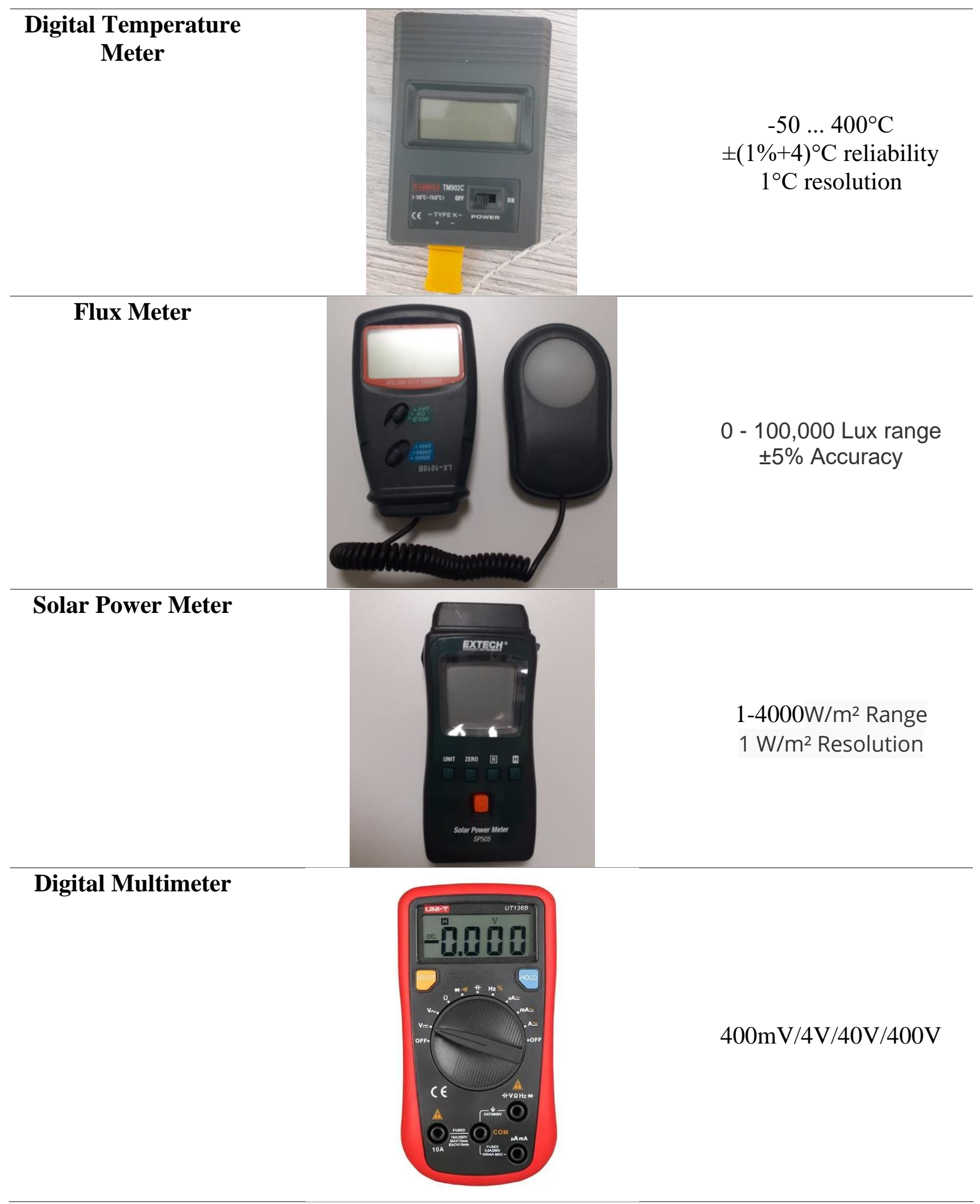




\section{Results}

In solar simulator including fan cooling system, from ambient temperature to $50{ }^{\circ} \mathrm{C}$, by activating heater, solar simulator temperature is increased with steps of $2^{\circ} \mathrm{C}$ and open circuit voltage of individual solar modules are recorded. Average of open circuit voltage of two identical solar modules is depicted as below.

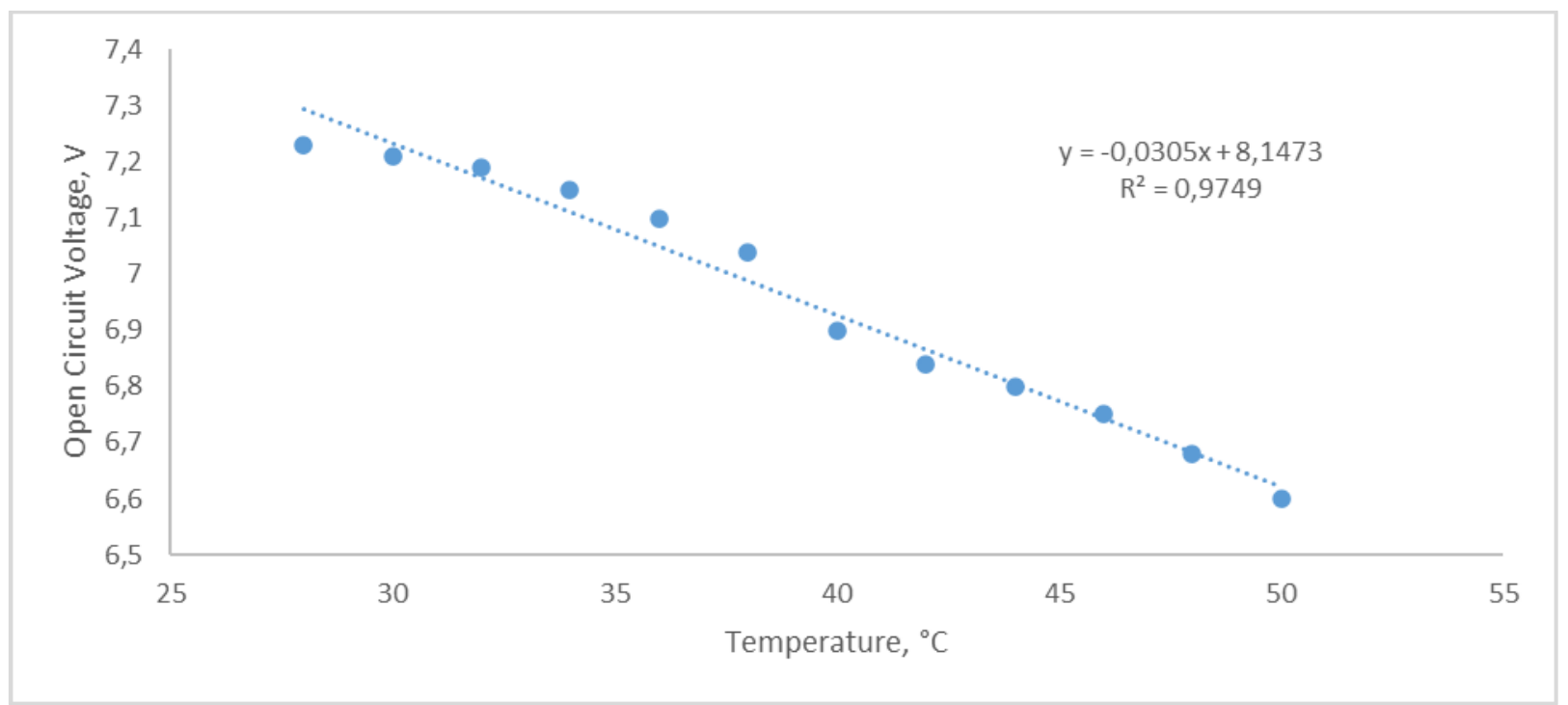

Figure 3. Average $V_{o c}$ value of two Identical Solar Module vs. Temperature

Values of two identical LED light sources are measured as 3860 lux and $50 \mathrm{~W} / \mathrm{m}^{2}$ measured via lux meter and solar watt meter, respectively.

\section{Discussion}

When the experimental results, above, are investigated, it can be seen that there is a linear relation between open circuit output voltage and temperature. $\mathrm{R}$-squared, $\mathrm{R}^{2}$, shows how strong the relationship between regression and experimental data. In physical studies, limit of R-squared for very strong relationship is 0.9 . In this relationship it is very strong relationship. Validation of (2) is done, as the temperature increases output voltage decreases, or vice versa. On the other hand, slope of linear regression gives meaningful information about efficiency drop. If the efficiency drop for every $1{ }^{\circ} \mathrm{C}$ temperature increase is considered, which is $\% 0.4 \mathrm{~K}^{-1}$, it is nice to obtain this experimental results by considering slightly increasing of short circuit current. Also, obtained result is comparable with output voltage variation over temperature rise in [2]. In experimental procedure, limiting factor of silicon solar cell is upper working temperature of $\mathrm{PV}$ module. Beyond $50{ }^{\circ} \mathrm{C}$, it is risky to take experimental data. On the other hand, lower than $27^{\circ} \mathrm{C}$ is not possible to take because of weather for summer time. If the LED light source lux and power values are compared, it can be seen that, if sun could be replaced with two identical light sources, conversion of 3860 lux would be $30 \mathrm{~W} / \mathrm{m}^{2}$. This shows spectral similarity of solar simulator to sun. It is possible to conduct experiment even at night, closed weather of winter time via proposed solar simulator including fan cooling system. 


\section{Conclusions}

Photovoltaic panels are very strong candidate to take place as renewable energy resource nowadays. If the energy demand of world is considered how important to obtain higher power from photovoltaic modules. Double faced photovoltaic modules are utilized to double obtained power. On the other hand, researchers study on parameters affecting PV module performance. Temperature is the most studied parameter in literature. Many methods are introduced to reduce operating temperature of solar modules. In this study, fan cooling method is studied via proposed solar simulator system. Very strong linear relationship between temperature and open circuit output voltage is obtained and statistically it is validated. It is showed that one of the strongest factors affecting output voltage is temperature. By considering solar simulator performance, it can be said that proposed systems behaves like a real sun spectrally. As a further development, cooling system could be computer controlled fan cooling system. All in all, thanks to proposed system, natural limitations of sun are broken and experimental freedom is introduced.

\section{References}

[1] Zhu et al. Online modelling and calculation for operating temperature of silicon-based pv modules based on bp-ann. International Journal of Photoenergy.2017;2017:1-13.

[2] Chander, S., Purohit, A., Sharma, A., Arvind, Nehra, S. P., \& Dhaka, M. S. A study on photovoltaic parameters of mono-crystalline silicon solar cell with cell temperature. Energy Reports.2015;1:104-09.

[3] Erel Ş. A Study of Cooling Effect on the Operation of a Polycrystalline Silicon Solar Cell. International Journal of Engineering Research and Development.2009;1:47-49.

[4] Dubey, S., Sarvaiya, J. N., \& Seshadri, B. Temperature Dependent Photovoltaic (PV) Efficiency and Its Effect on PV Production in the World - A Review. Energy Procedia.2013;33:311-21.

[5] Durisch, W., Bitnar, B., Mayor, J.-C., Kiess, H., Lam, K., \& Close, J. Efficiency model for photovoltaic modules and demonstration of its application to energy yield estimation. Solar Energy Materials and Solar Cells.2007;91:79-84.

[6] Green, M. A. General temperature dependence of solar cell performance and implications for device modelling. Progress in Photovoltaics: Research and Applications.2003;11:333-40.

[7] Mavromatakis, F., Kavoussanaki, E., Vignola, F., \& Franghiadakis, Y. Measuring and estimating the temperature of photovoltaic modules. Solar Energy.2014;110:656-66.

[8] L. D. Murillo-Soto and C. Meza. A Simple Temperature and Irradiance-Dependent Expression for the Efficiency of Photovoltaic Cells and Modules. 2018 IEEE 38th Central America and Panama Convention (CONCAPAN XXXVIII). 2018;2018:1-6.

[9] G. Notton, C. Cristofari, M. Mattei, and P. Poggi. Modelling of a double-glass photovoltaic 
module using finite differences. Applied Thermal Engineering.2005;25:2854-2877.

[10] Y. Riffonneau, S. Bacha, F. Barruel, and S. Ploix. Optimal Power Flow Management for Grid Connected PV Systems With Batteries. IEEE Trans. Sustain. Energy.2011;2:309-20.

[11] F. Dincer and M. E. Meral. Critical Factors that Affecting Efficiency of Solar Cells. SGRE.2010;01:47-50.

[12] P. SINGH, S. SINGH, M. LAL, and M. HUSAIN. Temperature dependence of I-V characteristics and performance parameters of silicon solar cell. Solar Energy Materials and Solar Cells.2008;92:1611-16.

[13] P. Singh and N. M. Ravindra. Temperature dependence of solar cell performance-an analysis. Solar Energy Materials and Solar Cells.2012;101:36-45.

[14] E. Skoplaki and J. A. Palyvos. On the temperature dependence of photovoltaic module electrical performance: A review of efficiency/power correlations. Solar Energy.2009;83:614-24. 